\title{
The Evaluation of Campus Library Document Delivery Service
}

\begin{abstract}
A campus delivery service is one way to increase accessibility of library materials. This report provides an overview of such a service, evaluates its performance, notes the economic implications, and concludes that the service can solve some of the problems of decentralized collections.
\end{abstract}

$\mathrm{H}$ OW EFFECTIVE ARE ACADEMIC LIBRARIES as service agencies? It is a question for which there are no pat answers. Many factors can affect service: the geographical organization of a campus, the organization of the library system, the attitudes of the teaching faculty, library faculty and the administration, the size of the collection. However, it is probably safe to assume that most university libraries are under-utilized. Although the library is often labeled the heart of a university, it is more likely to function as an instructional appendage.

Do researchers turn to the library when they need information? It is well known that many researchers have developed alternate communication channels which for them are more responsive. In general, researchers secure information from the sources most convenient to them. In 1963 Slater found that the distance from a researcher's office to his technical library influenced his use of that library. ${ }^{1}$ Allen and Rosenberg found that information channels are selected on the basis of ease of use and accessibility rather than on the

Richard M. Dougherty is university librarian, University of California, Berkeley. amount of information those channels are expected to generate. ${ }^{2}$ Robert Taylor has stated that a system which provides easier access, specifically physical convenience, will be more effective than a system which is concerned only with the quality of the scheme of subject organization. ${ }^{3} \mathrm{C}$. Walter Stone suggested that in the long run it may prove more effective and efficient to move information to people rather than move people to information. ${ }^{4}$ If ease and convenience are such potent influences on a user's behavior, then why not develop mechanisms to improve the ease to which a library's rich resources can be accessed?

A campus delivery service is one way to increase the accessibility of documents. A delivery service could enable a faculty member to telephone from his office for a specific item. The library could respond by retrieving the item from the stacks, checking it out, and delivering it either to the requestor's departmental office or directly to his office. This paper analyzes a document delivery service introduced at the University of Colorado; who used it, why it was used, the level of performance achieved, and the attitudes of users toward this innovative service. 


\section{OVERVIEW OF THE FACULTY Document Delivery Service}

On January 22, 1969 the library announced that commencing February 1, a library document delivery service for faculty, academic support staff and administrators would be inaugurated. Faculty members were informed that the experimental service was being tried in an effort to counter the difficulties of using the university's decentralized library system. The faculty document delivery service (FDDS) would be an attempt to reduce the frustrations experienced by researchers in locating materials. One day service was to be the objective. $^{5}$

The announcement further described the system: To obtain an item from the library, a requestor merely telephones the Circulation Department, using a special number, and provides the library assistant with whatever bibliographical information he or she has. The library staff member fills out all the necessary forms and delivers the item to the requestor's own office or departmental office, whichever location is specified. A special form is used to notify requestors when delivery of an item is delayed or undeliverable. A telephone recording device was available to accept requests when the office was not manned.

After six weeks, the director of li- braries circulated a second memorandum reporting the initial user reaction to FDDS. ${ }^{6}$ Ninety-four different faculty members had requested 502 items of which 380 were delivered, representing a 76 percent success. Of the 122 items not delivered, 19 were noncirculating titles, 21 were in circulation at the time the request was received, 34 items were not owned, and 22 requests were for items currently on order. Only 26 items could not be accounted for, which represented only 5.2 percent of the total requests processed.

Although FDDS proved to be an immediate success, the success was based on a great deal of careful preliminary planning. When the service was first proposed, staff reactions were generally favorable. However, there were fears that the service might prove to be an embarrassment because the library was not staffed to handle a large volume of requests. A contingency plan was formulated (although never used) so that additional staff could be assigned if the demand warranted.

Some staff members expressed reservations with the staffing patterns proposed by the administration. The FDDS was to be administered by a nonprofessional assisted by a clerk and student assistant. They felt that the FDDS would require professional expertise to decipher, com-

TABLE 1

USERS OF THE FDDS: ANALYSIS BY RANK AND/OR STATUS WITHIN THE UNIVERSITY

\begin{tabular}{|c|c|c|c|c|c|c|}
\hline \multirow[b]{2}{*}{ Rank/Status } & \multicolumn{2}{|c|}{ Total } & \multicolumn{2}{|c|}{ Respondents } & \multicolumn{2}{|c|}{ Nonrespondents } \\
\hline & No. & $\%$ & No. & $\%$ & No. & $\%$ \\
\hline Professor & 95 & 25 & 62 & 30 & 33 & 20 \\
\hline Associate Professor & 60 & 16 & 45 & 22 & 15 & 9 \\
\hline Assistant Professor & 97 & 26 & 62 & 30 & 35 & 21 \\
\hline Instructor & 35 & 9 & 14 & 7 & 21 & 12 \\
\hline Librarians & 3 & 1 & 2 & 1 & 1 & 1 \\
\hline $\begin{array}{l}\text { Teaching Assistants } \\
\text { Research Assistants }\end{array}$ & & & 7 & 3 & 15 & 9 \\
\hline $\begin{array}{l}\text { Kesearch Assistants } \\
\text { Graduate Assistants }\end{array}$ & 22 & 6 & 7 & 3 & & 8 \\
\hline Students & 7 & 2 & 5 & 2 & 2 & \\
\hline Administration \& Support Staff & 30 & 8 & 10 & 4 & 20 & 12 \\
\hline Visiting Faculty & 17 & 4 & 1 & 5 & 16 & 9 \\
\hline No Answer & 11 & 3 & - & $=$ & 11 & 6 \\
\hline Totals & $\overline{377}$ & $\overline{100}$ & $\overline{208}$ & $1 \overline{00}$ & $\overline{169}$ & $\overline{100}$ \\
\hline
\end{tabular}


plete, or correct inaccurate bibliographical citations. But without actual experience one could only speculate on the question. (Experience proved that very few submitted citations were garbled.)

A few key university administrators opined that the proposed service was tantamount to intellectual spoonfeeding. "Aren't faculty and students supposed to be able to use the library themselves?" is how they expressed the traditional view. The expenditure of funds to retrieve and deliver materials did not

TABLE 2

USERS OF THE FACULTY DOCUMENT DeLIVERY SERVICE

\begin{tabular}{lcr}
\hline \hline Category & Frequency & Percent \\
\hline Myself & 113 & 54 \\
Secretary & 36 & 17 \\
Myself \& Secretary & 45 & 22 \\
Graduate Assistant & $-\overline{3}$ & - \\
Other (not specified) & $\frac{8}{3}$ \\
No Answer & $\overline{208}$ & $\overline{4}$ \\
Total & & \\
\hline
\end{tabular}

carry a very high priority. Fortunately two administrators perceived the FDDS as a possible strategy to lessen frustrations associated with using a decentralized library system. The latter view prevailed and it was decided to offer the service on an experimental basis.

Users of the FDDS were broadly representative of the university community. A breakdown of ranks and university status is summarized in Table 1 . Teaching faculty comprised 79 percent of the total user population. During the first eighteen months over 33 percent of the faculty requested materials at least once.

Researchers from the humanistic and social science disciplines comprised 46 percent of the users. This was significant since some had doubted that the FDDS would be attractive to humanists due to a supposed preference for browsing. Researchers appointed to interdisciplinary institutes comprised 13 percent of the users. One conclusion gleaned from the first year's experience was that a campus document delivery service will attract a broad base of support.

Secretaries and other support staff often serve as the researcher's library surrogate. Almost 40 percent of the faculty delegated all or part of their FDDS transactions to secretaries (Table 2). Some faculty assigned their FDDS business to graduate assistants; unfortunate$\mathrm{ly}$, the questionnaire erroneously listed "graduate assistant" as "graduate department." Consequently use by graduate assistants is not accurately reflected in the results. ${ }^{7}$ Senior faculty are more likely to have assistants who can search and retrieve library materials. While not surprising, the pattern suggests that junior faculty may be more conversant with the library and its problems.

It would be wise if we librarians recognized that the reputation of our libraries rests largely with the successes and failures experienced by secretaries and assistants. The faculty as a group may comprise our most sophisticated users, but we know that many of them are not effective library users. One recently-completed study identified many faculty who were unaware of basic library services such as reference and interlibrary loan; some did not understand the purpose of a union catalog; and others could not differentiate between a card catalog and a computer produced book catalog. ${ }^{8}$ If the faculty become frustrated in their attempts to use a library, can we realistically expect their secretaries to fare better? The data indicates that some programs of library orientation and instruction might usefully be directed at those secretaries and graduate assistants who must use the library.

In the first year, 2,868 items were requested through the FDDS, while 3,600 items were picked up and returned to the library. Use summarized by month is presented in Table 3. The pattern of use approximates the academic calendar, 
TABLE 3

Faculty Document Delivery Transactions by Month FEBRUARx 1969-JanUaRY 1970

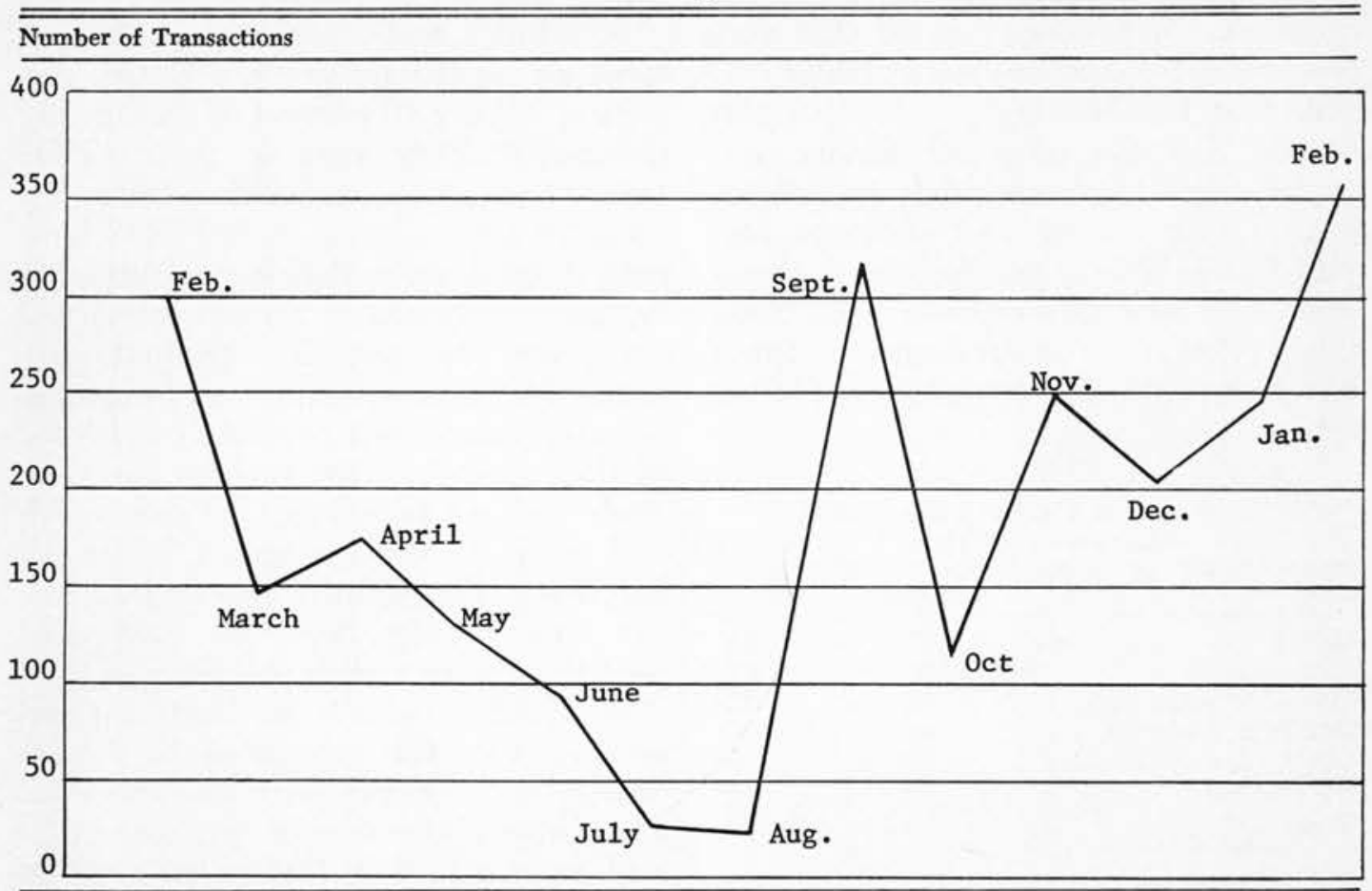

with the line increasing gradually throughout the fall, and the low point occurring during the months of July and August.

During the first half of the second year, 1,622 items were requested, a 95 percent increase over the first six months of the initial year, averaging 324 items compared to 166 items per month. Although 324 items comprised only a miniscule proportion of the total library circulation, the impact of the FDDS could not be judged solely on the volume of use.

Another measure of utility is the proportion of repeat users. Of the 377 users, 52 percent were repeaters. Furthermore, 54 percent of those who responded to an attitude questionnaire noted that the availability of the FDDS had altered their library use patterns.
Performance of the Faculty Delivery Service

At the outset it was not known how effectively and rapidly the FDDS could respond to specific requests for material. Pessimism was not unusual, for many on the staff had been conditioned by comments from users such as:

"Oh, I can expect to locate only about half the items I'm looking for...."

"I can never find anything I really need...."

"Nothing you ever want is properly shelved...."

This mental set in part accounted for the initial trepidations cited earlier. Fortunately neither the skepticism nor the pessimism lingered long.

Requests were satisfied at a level which far exceeded all expectations. During the first year, 69 percent $(3,083$ 
TABLE 4

DisPosition of FDDS REQUESTS wITHIN 23 HouRs OF RECEIPT

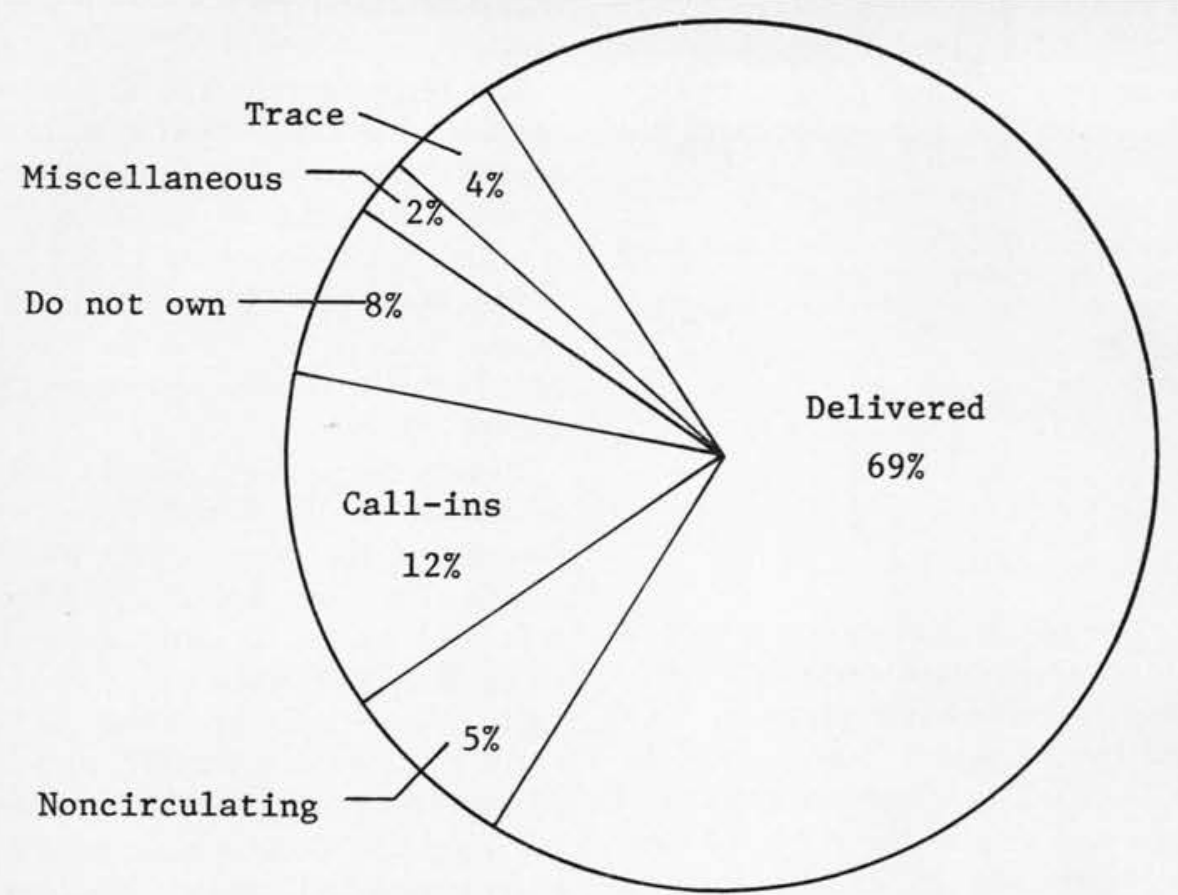

items) were delivered within one working day; 12 percent were delivered later (Table 4). Five percent of the items which could not be delivered were noncirculating items, 8 percent were items not owned (they were requested later through interlibrary loan), 2 percent were items on order but not yet received. Only 4 percent of the items requested were listed in the card catalog but could not be located. In other words, four out of five items were retrieved and delivered.

Users were asked to rate the speed of the FDDS on a five-step scale from slow to fast. The results clearly reflected a general satisfaction. A chi-square test was employed to determine if the responses deviated significantly from a distribution of random responses. The test revealed a significance $\mathrm{X}^{2}=199.97$ $(\mathrm{df}=4)$ at a .005 level of significance (Table 5).

Comments appended to several re- turned questionnaires clearly revealed some of the users' views:

"Expeditious."

TABLE 5

USER RATING OF THE SPEED OF THE FDDS FROM REQUEST TO DELIVERY

\begin{tabular}{|c|c|c|}
\hline Rating & Frequency & Percent \\
\hline $\begin{array}{ll}1 & \text { (slow) } \\
2 & \\
3 & \\
4 & \\
5 & \text { (fast) } \\
\text { No Answer }\end{array}$ & $\begin{array}{r}4 \\
3 \\
19 \\
104 \\
63 \\
15 \\
\end{array}$ & $\begin{array}{r}2 \\
1 \\
9 \\
50 \\
30 \\
7 \\
\end{array}$ \\
\hline Total & $\overline{208}$ & $\overline{99}$ \\
\hline
\end{tabular}

"FDDS is so fast I don't know how you do it."

"The service was fast 90 percent of the time."

Or best of all:

"The service is very fast . . but don't get complacent!"

The effectiveness of follow-up procedures designed to locate and deliver items which could not be delivered im- 
mediately was an important feature. Forty-two percent of the respondents indicated that the follow-up services were excellent and 31 percent reported that they were good (Table 6). Some respondents however did not understand the

TABLE 6

Rating of the FDDS Follow-up Procedures (CALL-INS, TRACES, NOTICES, ETC.)

\begin{tabular}{lcc}
\hline \hline Category & Frequency & Percent \\
\hline Excellent & 88 & 42 \\
Good & 64 & 31 \\
Fair & 13 & 6 \\
Poor & 1 & 1 \\
Don't Know & $\mathbf{4 2}$ & 20 \\
Total & 208 & 100 \\
\hline
\end{tabular}

implications of the question; in fact 20 percent even admitted their ignorance. How many faculty know precisely what is meant by the terms "trace," "call-in," "notice," etc.? The observed pattern of responses underscores the need for more intensive publicity to explain what is meant by a follow-up service.

\section{User Attrtude SuRvey}

In the fall of 1970 a questionnaire was prepared and distributed to all recorded users of the FDDS. The survey was designed to elicit reactions to the service, its performance, and the priority users might assign to the FDDS during a time of tight budgets. The survey also generated the data presented earlier in this paper. The questionnaire was brief, consisting of only nine closed-end questions. A little space was allotted for additional comments. The questionnaire was distributed by mail with no followups.

The response rate was 55 percent. Oppenheim has stated that a 40 to 60 percent response to a mail questionnaire is typical. ${ }^{9}$ In order to minimize the possibility of undetected biases, respondents and nonrespondents were compared in several ways to examine for possible differences between the two groups.

Resident teaching faculty comprised 67 percent of all FDDS users, while 94 percent of the respondents were teaching faculty (see Table 1). Administrators and university support staff were much less responsive to the questionnaire than their academic colleagues. Only one visiting faculty member out of seventeen responded. Also, very few teaching assistants and graduate assistants responded, partly because many were no longer on campus at the time the questionnaire was distributed. If administrators and visitors had been excluded from the user population, the overall faculty response would have equaled 63 percent. Since teaching and research faculty comprised the principal target group, the rate was judged adequate.

A comparison by broad discipline between respondents and nonrespondents also shows considerable similarity. Some divergence for humanists and social sci-

TABLE 7

Users of the FDDS: ANalysis by Broad Subject Disciplines

\begin{tabular}{|c|c|c|c|c|c|c|}
\hline \multirow[b]{2}{*}{ Discipline } & \multicolumn{2}{|c|}{ Total } & \multicolumn{2}{|c|}{ Respondents } & \multicolumn{2}{|c|}{ Nonrespondents } \\
\hline & Frequency & $\%$ & Frequency & $\%$ & Frequency & $\%$ \\
\hline Humanities & 89 & 23 & 41 & 20 & 48 & 28 \\
\hline Social Sciences & 86 & 23 & 59 & 28 & 27 & 16 \\
\hline Pure Sciences & 56 & 15 & 30 & 14 & 26 & 15 \\
\hline Applied Science & 80 & 21 & 51 & 25 & 29 & 17 \\
\hline Interdisciplinary Institutes & 50 & 13 & 25 & 12 & 25 & 15 \\
\hline Administrators & 7 & 2 & 2 & 1 & 5 & 3 \\
\hline No Answer & 9 & $\overline{2}$ & - & - & 9 & 5 \\
\hline Total & 377 & 99 & 208 & 100 & 169 & 99 \\
\hline
\end{tabular}


entists is apparent. But even here the difference does not appear to be significant (Table 7). ${ }^{10}$

A comparison of the number of uses recorded for respondents and nonrespondents showed no significant difference. Respondents borrowed an average of 3.84 items, whereas nonrespondents borrowed 2.11 items. A test of the difference of means showed no statistical significance between the two observed means.

Based on the similarity in characteristics between respondents and nonrespondents, it was concluded that the attitudes of respondents could be interpreted as reflecting those of the entire population.

The evaluation of the FDDS was divided into three parts. The first concentrated on an evaluation of overall performance, second, the impact on patterns of library use, and third, user's reactions to funding a delivery service during a period of tight budgets.

Sixty-eight percent of the respondents rated the FDDS as excellent and 23 percent rated the service as good (Table 8).

TABLE 8

RATiNg OF THE FDDS SERvice by UsERS

\begin{tabular}{lcc}
\hline \hline Category & Frequency & Percent \\
\hline Excellent & 143 & 68 \\
Good & 49 & 23 \\
Fair & 2 & 1 \\
Poor & 2 & 1 \\
No Answer & 12 & 6 \\
Total & 208 & 99 \\
\hline
\end{tabular}

Although the term "excellent" is subject to different interpretations, the validity of this positive rating was supported by a chi-square analysis which tested the null hypothesis that no relationship existed between those who rated the FDDS excellent and those who reported that the service had caused a change in their library use patterns from users who rated the service as good, fair, or poor and who reported that their library use patterns had not been altered. The chi- square analysis of independence was found to be $\mathrm{X}^{2}=5.6$ which is significant at a .95 level. The contingency coefficient value was found to be. 17 .

The comments appended to the questionnaires also reflected a variety of interesting attitudes:

FDDS is perhaps the most useful campus service to me as a faculty member. I have been very satisfied with the service since the beginning and I am desirous to see it continue and prosper.

This is one of the best things to happen to me and my students in the last ten years, now I spend time thinking (hopefully) and planning rather than doing routine searching. Please retain it.

I've now left the university, but since this questionnaire was forwarded to me and I was very enthusiastic about the service, I wanted to respond.

If I had the time I would fill the page with superlatives about the entire approach of FDDS. The idea and its implementation are great. Shortly, I will be moving to another university and $I$ pray that FDDS is a part of their $l i$ brary services.

This is the best damn service the library has ever offered-keep it going.

Only a few reservations were expressed. One regular library user stated that the service was completely superfluous to him because the library was his work place. Another respondent chastised the FDDS, noting that his first attempt had been a complete failure: the book could not be found by the FDDS staff, yet he had found it himself within a few minutes. Not surprisingly, he had not tried the service since. He did add that the service would be important if it could be made to work!

The FDDS did affect the library use habits of many users. Fifty-four percent of the respondents revealed that the FDDS had altered their patterns of use. As previously noted, a chi-square test for independence suggested the ex- 
istence of a relationship between those who rated the service excellent and those who had changed their patterns of use (Table 9).

TABLE 9

Did FDDS Change Your Pattern of LIBRARY UsE?

\begin{tabular}{lcc}
\hline \hline Answer & Frequency & Percent \\
\hline Yes & 112 & 54 \\
No & 75 & 36 \\
No Answer & $\underline{21}$ & 10 \\
Total & $\mathbf{2 0 8}$ & 100 \\
\hline
\end{tabular}

Over 90 respondents appended explanations as to why the FDDS had altered their use patterns. The most commonly cited reasons, with number of times cited were:

1. Saves time (Time was usually defined to include traveling, searching, and retrieving.) (23 times)

2. The library is now easier to use, consequently my usage has increased. (22 times)

3. The library is now more convenient to use. (6 times)

4. No longer have to return books to the library. (4 times)

5. Office is so far away from the branch that without the FDDS I would not bother to borrow materials. (3 times)

Most comments could be translated into savings in time, simplification in accessing materials, and greater convenience.

Explanations citing why the FDDS had not caused a change were also revealing. Five persons said that they were browsers who wished to retain direct contact with materials. Two who rated the service excellent candidly admitted that the service hadn't changed their use patterns because they could not shake their personal, long-standing habits. Three users noted that, since they had to use the library's card catalog anyway, they might as well pick up their own materials.

The only FDDS-induced change which might be interpreted as negative is that some users now make fewer trips to the library. Several individuals observed that they no longer personally returned books to the library. If library effectiveness is based on the number of users who enter the building, a document delivery service could have negative implications.

Respondents were asked to rate the importance of the FDDS during a time of tight budgets: that is, did they rate the service as essential, important, convenient, or a luxury to their personal library needs. The replies can be judged only as tentative since the users were not confronted with the necessity of making a real choice among resources; nevertheless, the pattern of responses is worth noting.

Almost half judged the FDDS as being convenient, only 9 percent labeled the FDDS as a budgetary luxury (Table 10). Forty-three percent assessed the service as being either important or essential to the achievement of their work. ${ }^{11}$

TABLE 10

Rating of the FDDS In a TrMe of TIGHT BuDgets

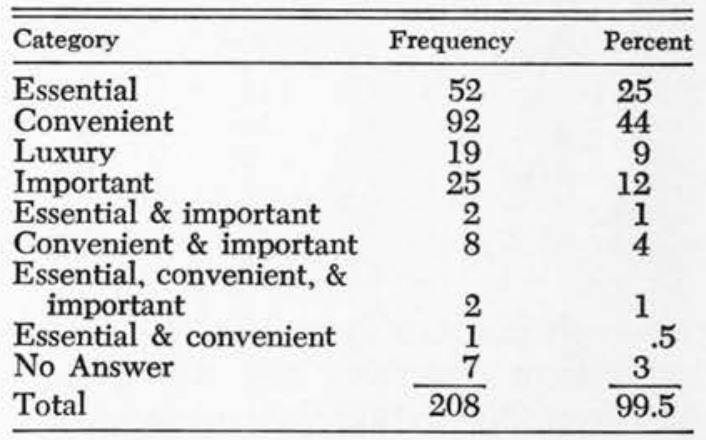

The FDDS was also evaluated by an analysis of the frequency of use compared against individual ratings (Table 11). Clearly, as the frequency of use increases so does the perception of importance. A chi-square test of independence supported the hypothesis that the distributions are statistically independent. 
TABLE 11

Comparison Between Frequency of USE AND RATING OF THE FDDS

\begin{tabular}{ccc}
\hline \hline & \multicolumn{2}{c}{ Rating } \\
\cline { 2 - 3 } Frequency of Use & $\begin{array}{c}\text { Convenient } \\
\text { or Luxury }\end{array}$ & $\begin{array}{c}\text { Important, } \\
\text { Essential, or Both }\end{array}$ \\
\hline $1-2$ & 73 & 35 \\
$3-4$ & 27 & 19 \\
$5-6$ & 5 & 8 \\
$7-8$ & 1 & 8 \\
$9+$ & 4 & 20 \\
\hline
\end{tabular}

$\left(\mathrm{X}^{2}=30.4 ; \mathrm{df}=4, .95\right.$ level of significance, critical $\mathrm{X}^{2}=9.49$ ).

\section{ECONOMIC IMPLICATIONS}

Cost studies of the FDDS were not conducted. The operating costs for the first year totaled $\$ 9,500$. Included in the figure are personnel costs, rental of a delivery truck, a telephone answering recorder, and supplies and forms. The total cost prorated on a per request basis yields a cost per transaction of $\$ 3.31$. This gross costing method actually overstates the unit cost, since the person assigned to operate the FDDS devoted only 60 to 70 percent of his time to FDDS related tasks. During the remainder he supervised stack workers and performed other duties within the Circulation Department.

If one considers the hourly salary of the average faculty member, and the time required to travel to the library to search, retrieve, check out, and return to his office, the operations of the FDDS are cost effective. For example, a faculty member earning $\$ 12,000$ a year on a nine month contract earns almost nine dollars per hour. He would have to complete his library visit in 22 minutes to match the costs of the FDDS.

However, even if unit costs could be reduced to as little as one dollar, or better yet to fifty cents per transaction, the impact would be obscured because some of the costs of retrieving library materials are hidden. Faculty members now fend for themselves. What the FDDS does is to conserve the time of the uni- versity's most important resource-its faculty. On this point a physicist cogently observed:

One way economists judge the value of a "good" service is how much one would pay to have the service. On this basis, I would not consider it excessive to pay $\$ 50.00$ per year from my research grant (if NSF would permit) or $\$ 10.00$ per year from my own pocket.

Budgeteers and legislators are conditioned to measure effectiveness primarily on costs saved. But how does one measure quantitatively the value of library resources or of an education? A service might be more usefully judged on whether it increases utilization of the library. In economic terms we are comparing a $\$ 9,500$ expenditure as one means of encouraging greater use of a resource costing more than two million dollars per year to maintain.

The potential scope and impact of a faculty document delivery service are clearly mirrored in the following reactions:

Our institute library is very specialized. The delivery service helped compensate for these lacks.

FDDS is essential since books are scattered around the several libraries, many books are missing or reserved. FDDS helps my teaching and research tremendously. I have recommended the system to many other universities. It is one of the few things I can be proud of concerning this university's operation.

Without the FDDS this book would not have been published. (This statement appeared in the foreword of a book authored by a member of the faculty.)

Please keep the service; it is essential to me for I have a broken foot.

\section{Conclusions}

The FDDS was able to deliver fourfifths of the items requested by mem- 
bers of the teaching and research faculty. We do not know how this level of performance would compare with performances at other institutions, but it is probable that most research libraries can supply more materials than most users assume. ${ }^{12}$

The FDDS was well received by the majority of its users. Over half of those who used the service reported that it had altered their library use patterns. Initially library staff members feared that the library would be swamped and overwhelmed by requests. The predicted high demand level did not materialize. One explanation can be found in the literature of innovation diffusion. Research in this field rationally explains the process by which people adopt new ideas. In short, a user will not automatically adopt a new library service even though it will "improve" his access to materials; he must first become aware of the service and be sufficiently interested to give the idea a trial; the trial must then prove successful before the idea is finally adopted and the change in behavior is complete. ${ }^{13}$

An FDDS service can be operated on a cost-effective basis, particularly if cost effectiveness is translated into hours saved. It is our belief that the time saved for users should be considered as one measure of library effectiveness. Likewise the impact of a service on the intensity of library use should also be adopted as a measure of effectiveness. Cost figures in isolation provide a distorted, incomplete picture.

The FDDS helped to ameliorate the inconveniences associated with using a decentralized collection. Respondents reported that the FDDS saved travel time and solved the aggravating problem of inadequate parking. One initial objective of the FDDS was to provide an alternative channel for researchers working in interdisciplinary institutes. To this end the delivery service succeeded.

In summary, a document delivery service may offer a viable alternative to small decentralized branches. We still need to learn more about the day-to-day material use patterns of researchers. If one could neutralize the political and emotional pressures, it might be discovered that departmental libraries do not offer the most effective pattern of library organization. For example, if a departmental library is used primarily to keep current, a reading room stocked with selected current journals and reference books backed up by a strong central collection, coupled with a document delivery system might offer a more responsive organization. A document delivery system will not solve all the problems caused by a decentralized collection, but it will lower some barriers to use perceived by some researchers.

\section{REFERENCES}

1. M. Slater, "Types of Use and User in Industrial Libraries: Some Impressions," Journal of Documentation 19:12-B (March 1963).

2. T. J. Allen and P. G. Gerstberger, "Criteria for Selection of an Information Source," (MIT, Working paper, p. 284-7) Sept. 1967; V. Rosenberg, "Factors Affecting the Preferences of Industrial Personnel for Information Gathering Methods," Information Storage and Retrieval 3:119 (July 1967).

3. R. S. Taylor, "Questions Negotiation and Information Seeking in Libraries," CRL 29:3 (May 1968), p. 193.
4. C. Walter Stone, "The Library Function," Library Trends 16:2 (Oct. 1967), p. 185.

5. Memorandum to members of the University of Colorado faculty, Boulder campus from Ralph E. Ellsworth, Director of Libraries, Boulder, Colorado, January 22, 1969.

6. Memorandum to members of the University of Colorado faculty, Boulder campus from Ralph E. Ellsworth, Director of Libraries, Boulder, Colorado, April 17, 1969.

7. An NSF-supported study at Syracuse University (GN-32381) which is investigating how faculty use libraries, supported the contention that graduate assistants often 


\section{Document Delivery Service / 39}

use the library in behalf of a faculty member.

8. L. E. Leonard, et al, Centralized Book Processing: A Feasibility Study Based on Colorado Academic Libraries (Metuchen, N.J.: Scarecrow Press, Inc., 1969), p. 21143.

9. A. N. Oppenheim, Questionnaire Design and Attitude Measurement (New York: Basic Books, 1966), p. 34.

10. No analyses based on broad subject disciplines were undertaken. The distinction among traditional academic labels has become so muddled by the emergence of cross-disciplinary programs that many categorizations would be artificial and arbi- trary. The analysis was used only as a check to compare respondents and nonrespondents.

11. "Convenient" and "luxury" were interpreted to mean that the service rated a low priority, and "essential" or "important" as indicators that the FDDS deserved a higher priority. Some who labeled the service as convenient nevertheless appended notes indicating that they very much wished to see the FDDS retained.

12. The expectation rates of users is presently being investigated under NSF Grant GN32381.

13. E. M. Rogers, Diffusion of Innovation (New York: Free Press of Glencoe, 1962). 